\title{
The next biotech superpower
}

\author{
China is set to challenge the pre-eminence of the US drug market. If it can address gaps in its R\&D ecosystem and \\ clinical infrastructure, it may even become a home for biotech innovators.
}

or the past 30 years, the United States has reigned supreme as a base to launch biopharmaceutical products. Biotech companies across the globe have viewed the US market as the world's most lucrative and largest prize, providing access to 327 million consumers via the globe's premier drug regulatory agency and a reimbursement system that lays out $\sim \$ 400$ billion for drug sales every year. Just a few years ago, the contrast with China could not have been starker: a laggard market dominated by generics companies of variable quality; an impenetrable regulatory and reimbursement system beset by red tape, corruption and cronyism; and a creaking healthcare system ill adapted to deliver products to patients. Recently, however, government reforms, massive private and public investment and returning expatriates have transformed the Chinese sector, turning it into the world's second-largest biopharmaceutical market, with $\$ 137$ billion in sales last year. The first shoots of homegrown drug discovery and development are emerging. And even if Chinese companies' near-term focus is on unmet needs of the country's aging population, their gaze is beginning to turn abroad, auguring profound changes for the global biopharmaceutical market of the future.

This issue's Feature provides a detailed look at China's drug market and biotech sector. It paints a picture of a rapidly evolving market that is fueling the growth of Chinese biopharmaceutical startups-growth one expert has called a "Cambrian explosion."

Details of just how many biotech companies comprise the Chinese sector are hard to come by and depend on how you define 'biotech'. The China Pharmaceutical Innovation and Research Development Association estimates that the domestic pharmaceutical sector comprises 4,441 companies. But most of these do not look anything like biotech firms. According to the World Health Organisation, the few Chinese drug makers that have an R\&D budget devote less than $5 \%$ of their sales revenue to it. In contrast, Western biotechs can spend as much as $50 \%$ or more of their sales income on $\mathrm{R} \& \mathrm{D}$.
Transitioning from China's highly fragmented sector of private or state-owned generics manufacturers and suppliers of active pharmaceutical ingredients to an innovative biotech sector is one of the stated goals of President Xi Jinping and his 'Made in China 2025' strategy for global leadership. Some experts estimate that the opening of the Chinese drug market to create an ecosystem more conducive to innovative biotech will result in the culling or consolidation of half of China's 4,000 generic companies. That change is already under way.

A key turning point came in 2015 when China's drug approval process was overhauled to be more in line with that of the United States. In return for a hefty hike in registration fees and more staff, China's drug regulator offered fast-track review and conditional approvals for drugs for unmet medical needs, dropped the requirement to perform clinical trials with Chinese patients in state-run labs, and relaxed rules obliging many firms to invest in local factories. At the same time, there has been a crackdown on quality standards for generics. These reforms have had a dramatic effect, discouraging generics firms from multiple 'copycat' drug approvals for the same brand drug, reducing the backlog in applications at the agency, and slashing wait times for foreign drug makers from years to months.

Policymakers also have had to administer strong medicine to China's byzantine drug pricing and reimbursement system. Markups in drug price and kickbacks to physicians in the overburdened hospital system have meant that the country spends $40 \%$ of its total healthcare expenditure on drugs (compared with an average of $20 \%$ in Organisation for Economic Co-operation and Development countries), leaving little for novel treatments. Through competitive tenders to reimbursement lists, authorities are now offering drug makers rapid access to China's market in return for drastic cuts in prices. This has radically increased both foreign companies' market access-40 of 41 products launched in China in 2017 originated from multinationals-and the number of medicines available to patients.
Many of China's biotech companies are focusing on a simple strategy: in-license drugs already approved in the West that are not available domestically. With millions of Chinese patients, clinical trial recruitment is easy, but the lack of expertise in running trials presents another bottleneck. It doesn't help that the industry's prevailing herd mentality uses up clinical resources on a few modalities and drug targets, as illustrated by the 100 domestic companies testing PD-1 or PD-L1 inhibitors across 196 local trials.

But a pivot to innovative drugs is underway. Several companies are bringing homegrown innovative drugs through their pipelines, mostly against established drug targets. Betta Pharmaceuticals, Jiangsu Hengrui Medicine, Chengdu Kanghong Pharmaceutical, Chipscreen Biosciences, BeiGene and Ascletis Pharma have all launched new drugs in China via this approach. A few, such as BeiGene, Ascletis, CStone Pharmaceuticals, CanSino Bio, Zensun Sci \& Tech and Pheromonicin Biotech, are developing drugs against new targets. Again, approval in China is the initial goal, but several are looking to the United States as well; in August, for example, Zensun received US fast-track designation for its recombinant protein Neucardin.

Most notable of all, last December, China approved roxadustat, a smallmolecule hypoxia inducible factor prolyl hydroxylase inhibitor from FibroGen China, AstraZeneca and Astellas. This represents the first time that an entirely novel firstin-class drug molecule has entered the Chinese market before being approved by any Western regulator. It remains to be seen how fast other companies opt for the China market before the United States.

A Chinese proverb states that "every journey of 1,000 miles begins with a single step." China is already several steps along the journey to a globally competitive drug market.

Published online: 5 November 2019 https://doi.org/10.1038/s41587-019-0316-7 